\title{
Using read codes to identify patients with irritable bowel syndrome in general practice: a database study
}

\author{
Elaine F Harkness ${ }^{1 *}$, Laura Grant ${ }^{1}$, Sarah J O'Brien², Carolyn A Chew-Graham ${ }^{3}$ and David G Thompson ${ }^{4}$
}

\begin{abstract}
Background: Estimates of the prevalence of irritable bowel syndrome (IBS) vary widely, and a large proportion of patients report having consulted their general practitioner (GP). In patients with new onset gastrointestinal symptoms in primary care it might be possible to predict those at risk of persistent symptoms. However, one of the difficulties is identifying patients within primary care. GPs use a variety of Read Codes to describe patients presenting with IBS. Furthermore, in a qualitative study, exploring GPs' attitudes and approaches to defining patients with IBS, GPs appeared reluctant to add the IBS Read Code to the patient record until more serious conditions were ruled out. Consequently, symptom codes such as 'abdominal pain', 'diarrhoea' or 'constipation' are used. The aim of the current study was to investigate the prevalence of recorded consultations for IBS and to explore the symptom profile of patients with IBS using data from the Salford Integrated Record (SIR).

Methods: This was a database study using the SIR, a local patient sharing record system integrating primary, community and secondary care information. Records were obtained for a cohort of patients with gastrointestinal disorders from January 2002 to December 2011. Prevalence rates, symptom recording, medication prescribing and referral patterns were compared for three patient groups (IBS, abdominal pain (AP) and Inflammatory Bowel Disease $(\mathrm{BDD})$ ).

Results: The prevalence of IBS (age standardised rate: 616 per year per 100,000 population) was much lower than expected compared with that reported in the literature. The majority of patients (69\%) had no gastrointestinal symptoms recorded in the year prior to their IBS. However a proportion of these (22\%) were likely to have been prescribed NICE guideline recommended medications for IBS in that year. The findings for AP and IBD were similar.

Conclusions: Using Read Codes to identify patients with IBS may lead to a large underestimate of the community prevalence. The IBS diagnostic Read Code was rarely applied in practice. There are similarities with many other medically unexplained symptoms which are typically difficult to diagnose in clinical practice.
\end{abstract}

Keywords: Irritable bowel syndrome, Read Codes, Functional gastrointestinal disorders, Medically unexplained symptoms, Primary care, General practitioners

\footnotetext{
* Correspondence: Elaine.F.Harkness@manchester.ac.uk

${ }^{1}$ Institute of Inflammation and Repair, Stopford Building, University of

Manchester, Oxford Road, Manchester M13 9PL, UK

Full list of author information is available at the end of the article
} 


\section{Background}

Irritable Bowel Syndrome (IBS) is a common gastrointestinal condition defined as 'a functional bowel disorder in which abdominal pain or discomfort is associated with defecation or a change in bowel habit, and with features of disordered defecation' [1]. Prevalence estimates for IBS appear to vary widely according to the criteria used, population studied, the mode of study delivery and type of prevalence estimate. Typically estimates range between $2 \%$ and $22 \%$ in western countries [2]. In the UK, a community survey estimated the prevalence of IBS to be $10.5 \%$ with over half of patients having consulted their general practitioner (GP) within the past six months [3].

Medical management of IBS symptoms is empiric usually involving anti-spasmodics, anti-diarrhoeals or laxatives as appropriate to symptoms; and antidepressants, particularly low-dose tricyclic antidepressants [4]. Unfortunately, for some patients medical management is unsatisfactory. For patients with symptoms resistant to conventional medical therapy, current guidelines recommend referral for psychological intervention to cognitive behavioural therapy (CBT) or hypnotherapy [4].

Halder et al. [5] showed that in patients with new onset gastrointestinal symptoms in primary care it might be possible to predict those at risk of persistent symptoms. Thus it might be possible to identify those patients at risk of doing worse and fast-track them to these therapies. This should lead to less distress and lower healthcare utilisation for these patients in the long run. We aimed to test this finding prospectively as a part of a NIHR (National Institute for Health Research) programme of work (RP-PG-0407-10136). However, one of the difficulties encountered in previous work on IBS within primary care is the identification of patients.

GPs use a variety of Read Codes to describe patients presenting with IBS. Furthermore, in a qualitative study to explore GPs attitudes and approaches to defining, diagnosing and managing patients with IBS in primary care we found that, despite recent guidelines from the National Institute for Health and Clinical Excellence (NICE) [4], IBS is still regarded as a diagnosis of exclusion, and GPs are reluctant to add the IBS Read Code to the patient record until more serious conditions are ruled out [6]. As a consequence, symptom codes such as 'abdominal pain', 'diarrhoea' or 'constipation' are Read coded in the patient record. To our knowledge the range of Read Codes used by GPs to define IBS has not previously been investigated. We therefore used a database study to investigate the use of Read Codes in patients with IBS. In addition, two recent systematic reviews have found that the quality of coding of morbidities within primary care varied, and this has been attributed to the distinctiveness of the diagnosis $[7,8]$. We therefore also wished to explore the differences in coding between a 'functional' and an 'organic' disorder.

\section{Aim}

The aim of the current study was to investigate the prevalence of recorded consultations for IBS and to explore the symptom profile of patients with IBS using data from the Salford Integrated Record (SIR). Patients with IBS were our primary group of interest, but we were also interested in how GPs coded patients with other gastrointestinal conditions, to determine whether there were any differences in coding practices across conditions. Patients with abdominal pain (AP) were chosen because it is the main feature of IBS, and must be present with two other symptoms to fulfil a diagnosis of IBS [4]. In addition, we selected patients with IBD because IBD is an organic disorder in which patients present with similar symptoms to IBS and we wished to explore differences in coding practices between a 'functional' and an 'organic' disorder.

\section{Methods \\ Setting}

The setting for this study was Salford Primary Care Organisation, North West of England with an estimated population of 228,992 in 2010 [9].

\section{Population}

All patients registered with the 52 General Practices in Salford Primary Care Organisation.

\section{Data collection and coding}

The SIR is a local patient sharing record system which integrates primary care, community care and secondary care information into one continuous electronic health record per patient. It is especially important for patients with long-term conditions, who may see many health professionals, saving the patient from having to repeat the same information multiple times. An anonymised dataset is made available for research through the auspices of North West e-Health.

Electronic clinical records from the SIR were obtained for a cohort of patients based on symptom and diagnostic codes for gastrointestinal disorders for the period January 2002 to December 2011. Information was supplied in two separate files: the first contained anonymised patient identifiers, sex and year of birth; the second contained journal entry identifier, anonymised patient identifier, date of journal entry, Read Code description and Read Code. The files were matched on patient identifier, and checked for duplicates and anomalies. Duplicate records and patients under the age of 17 were removed. Read Codes were then coded into a new variable to distinguish between symptom and/ or diagnostic codes, medication codes and referral codes. 


\section{Analysis}

For the study we carried out analysis on three groups. These were patients with:

a) IBS (Read Codes 14CF. and J521. including any subheadings)

b) abdominal pain (Read Codes 196.., 197.. and R090. including any subheadings)

c) Inflammatory Bowel Disease (IBD) (Read Codes J4... (without subheadings), J40.. and J41.. including any subheadings)

For each group of patients we identified an index episode of IBS, abdominal pain or IBD. For each index episode, an index date was created based on the date for that particular journal entry. For each condition we then looked one year pre and post the index date to determine:

i) Symptoms/diagnoses recorded pre and post IBS, abdominal pain and IBD

ii) Medications prescribed pre and post IBS, abdominal pain and IBD

iii) Referrals to gastrointestinal (GI) specialists pre and post IBS, abdominal pain and IBD

The index episode was taken as the first occurrence of IBS, abdominal pain or IBD. The date of this episode was then used to calculate the number of days between the index episode and all corresponding journal entries for the same patient. Where the journal entry date was the same as the index date symptoms/diagnoses were included in the previous year and medications and referrals were included in the year after the index episode. Pre- episode data was based on those with an index episode between 2003 and 2011 (so that only those with a complete year of data available before the index year were included), likewise post-episode data was based on those with an index episode between 2002 and 2010.

We also calculated prevalence estimates based on Salford population data. Population data was obtained from the Office of National Statistics (ONS) website for Salford Primary Care Organisation [9]. Rates were standardised to the Greater Manchester population for 2006. This includes the population of the ten primary care organisations within the Greater Manchester area, which is roughly 2.5 million.

\section{Results}

There were 8,444 patients in Salford with an IBS Read Code recorded in the years 2002 to 2011. AP and IBD were Read Coded for 42,490 and 1,510 patients respectively.

IBS and AP were much more common in females, whereas a similar proportion of males and females had IBD (Table 1). The highest proportion of those with IBS,
Table 1 Demographic information for patients with IBS, AP and IBD, Salford 2002-2011

\begin{tabular}{|c|c|c|c|c|c|c|c|}
\hline & \multicolumn{2}{|c|}{ IBS } & \multicolumn{2}{|c|}{ AP } & \multicolumn{2}{|c|}{ IBD } \\
\hline & & $\mathrm{n}$ & $\%$ & $\mathrm{n}$ & $\%$ & $\mathrm{n}$ & $\%$ \\
\hline Female & & 6137 & 72.7 & 26071 & 61.4 & 755 & 50.0 \\
\hline \multirow[t]{3}{*}{ Age } & $18-39$ & 4373 & 51.8 & 19662 & 46.3 & 629 & 41.7 \\
\hline & $40-59$ & 2703 & 32.0 & 13379 & 31.5 & 487 & 32.3 \\
\hline & $60+$ & 1368 & 16.2 & 9449 & 22.2 & 394 & 26.1 \\
\hline
\end{tabular}

AP or IBD was in those aged 18-39 and declined with age. More patients with IBD were aged 60 or over $(26 \%)$ compared with those aged 60 or over with IBS (16\%) and AP (22\%).

\section{Prevalence estimates}

The age standardised rates for IBS, AP and IBD per year per 100,000 population were $616,3,606$ and 139 respectively. Figure 1 shows the age standardised rates per 100,000 population for IBS, AP and IBD by gender in Salford for the years 2002-2011. Rates have been standardised to the Greater Manchester population. The rates for IBD have remained stable across the ten year period for both males and females. IBS shows a similar pattern in males and females with a slight increase in prevalence rates up to 2006 before levelling out over the second half of the ten year period. The rates of AP on the other hand increased considerably in both males and females from 2002 to about 2009, after which they have levelled out for both males and females.

\section{Symptoms pre and post IBS, AP or IBD}

Table 2 shows the number of symptoms/diagnoses one year prior to and one year after the index episode of IBS, $\mathrm{AP}$ and IBD. The most commonly reported symptoms in the year prior to IBS were AP (19.5\%), diarrhoea (6.1\%) and bloating (3.8\%). However, for most patients

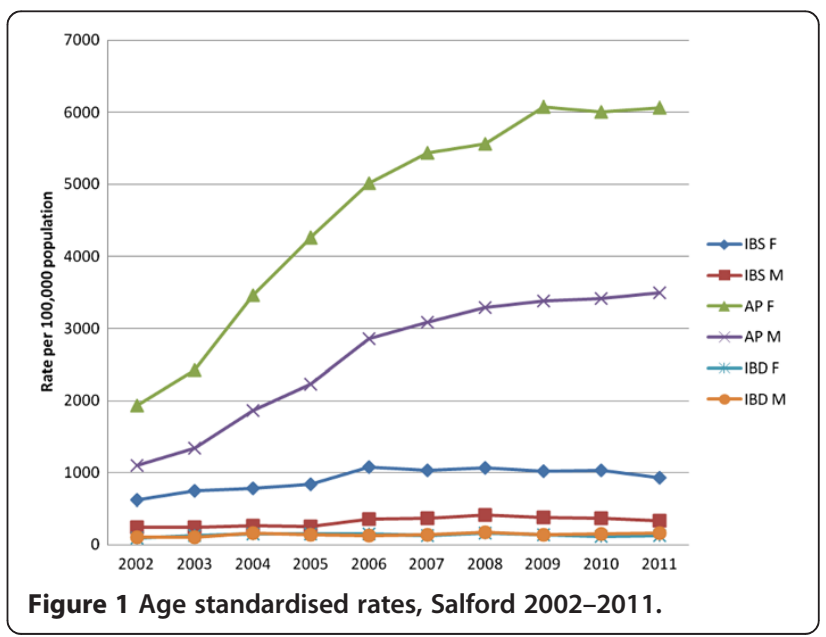


Table 2 Number (\%) of symptoms pre and post IBS, AP and IBD, Salford 2002-2011

\begin{tabular}{|c|c|c|c|c|c|c|c|c|c|c|c|c|}
\hline \multirow[b]{2}{*}{ Symptoms/diagnoses* } & \multicolumn{2}{|c|}{$\begin{array}{c}\text { Pre IBS } \\
(n=7728)\end{array}$} & \multicolumn{2}{|c|}{$\begin{array}{c}\text { Post IBS } \\
(n=7665)\end{array}$} & \multicolumn{2}{|c|}{$\begin{array}{c}\text { Pre AP } \\
(\mathrm{n}=39974)\end{array}$} & \multicolumn{2}{|c|}{$\begin{array}{c}\text { Post AP } \\
(\mathrm{n}=37851)\end{array}$} & \multicolumn{2}{|c|}{$\begin{array}{c}\text { Pre IBD } \\
(n=1336)\end{array}$} & \multicolumn{2}{|c|}{$\begin{array}{c}\text { Post IBD } \\
(n=1382)\end{array}$} \\
\hline & $\mathrm{n}$ & $\%$ & $\mathrm{n}$ & $\%$ & $\mathrm{n}$ & $\%$ & $\mathrm{n}$ & $\%$ & $\mathrm{n}$ & $\%$ & $\mathrm{n}$ & $\%$ \\
\hline Abdominal pain & 1509 & 19.5 & 1028 & 13.4 & - & - & 8683 & 22.9 & 212 & 15.9 & 144 & 10.4 \\
\hline Bloating & 291 & 3.8 & 137 & 1.8 & 411 & 1.0 & 374 & 1.0 & 8 & 0.6 & 7 & 0.5 \\
\hline Constipation symptom & 166 & 2.1 & 138 & 1.8 & 639 & 1.6 & 700 & 1.8 & 16 & 1.2 & 14 & 1.0 \\
\hline Change in bowel habit & 130 & 1.7 & 45 & 0.6 & 175 & 0.4 & 174 & 0.5 & 46 & 3.4 & 5 & 0.4 \\
\hline Diarrhoea symptoms & 475 & 6.1 & 256 & 3.3 & 1046 & 2.6 & 972 & 2.6 & 158 & 11.8 & 74 & 5.4 \\
\hline Nausea & 104 & 1.3 & 100 & 1.3 & 483 & 1.2 & 513 & 1.4 & 6 & 0.4 & 12 & 0.9 \\
\hline Vomiting & 72 & 0.9 & 67 & 0.9 & 583 & 1.5 & 583 & 1.5 & 11 & 0.8 & 19 & 1.4 \\
\hline Diarrhoea \& vomiting & 47 & 0.6 & 43 & 0.6 & 202 & 0.5 & 192 & 0.5 & 12 & 0.9 & 6 & 0.4 \\
\hline Tenesmus & 2 & 0.0 & 2 & 0.0 & 6 & 0.0 & 12 & 0.0 & 2 & 0.1 & 0 & 0.0 \\
\hline Faeces/motion symptoms & 31 & 0.4 & 34 & 0.4 & 72 & 0.2 & 80 & 0.2 & 8 & 0.6 & 4 & 0.3 \\
\hline None of the above symptoms & 5367 & 69.4 & 6062 & 79.1 & 36994 & 92.5 & 27010 & 71.4 & 930 & 69.6 & 1143 & 82.7 \\
\hline 1 of the above symptoms & 1950 & 25.2 & 1380 & 18.0 & 2699 & 6.8 & 9555 & 25.2 & 339 & 25.4 & 200 & 14.5 \\
\hline 2 or more of the above symptoms & 411 & 5.3 & 223 & 2.9 & 281 & 0.7 & 1286 & 3.4 & 67 & 5.0 & 39 & 2.8 \\
\hline Functional constipation & 151 & 2.0 & 121 & 1.6 & 511 & 1.3 & 573 & 1.5 & 20 & 1.5 & 21 & 1.5 \\
\hline Functional diarrhoea & 31 & 0.4 & 31 & 0.4 & 75 & 0.2 & 118 & 0.3 & 22 & 1.6 & 15 & 1.1 \\
\hline Gl infection & 84 & 1.1 & 63 & 0.8 & 295 & 0.7 & 295 & 0.8 & 18 & 1.3 & 8 & 0.6 \\
\hline IBS & - & - & 1090 & 14.2 & 747 & 1.9 & 1061 & 2.8 & 42 & 3.1 & 25 & 1.8 \\
\hline $\mathrm{IBD}$ & 33 & 0.4 & 40 & 0.5 & 128 & 0.3 & 204 & 0.5 & - & - & 391 & 28.3 \\
\hline
\end{tabular}

*Symptoms on the same day were coded as pre.

(69.4\%) no GI symptoms were recorded in the year prior to their IBS. Likewise in the year after the index episode of IBS most patients did not have any GI symptoms recorded (79.1\%), AP was the most commonly recorded symptom (13.4\%) and $14 \%$ of patients had a further episode of IBS recorded in the year after their index episode. IBD showed a similar pattern to IBS with the majority of patients (69.6\%) not having any symptoms recorded in the year prior to their IBD diagnosis. The most commonly reported symptoms were AP (15.9\%) and diarrhoea (11.8\%). In the year after the index episode of IBD, AP and diarrhoea were still the most commonly reported symptoms but the proportions tended to be lower (10.4\% and 5.4\% respectively). Almost a third of patients had a further episode of IBD recorded in the year after their index episode.

For patients with AP most patients (92.5\%) had no symptoms recorded in the year prior to their index episode of AP. In the year after their index episode, $23 \%$ of patients had a further AP episode, and $2.8 \%$ of patients had an IBS diagnosis.

The proportion of patients who reported two or more symptoms in the previous year or the year after IBS, AP or IBD was coded in $5 \%$ or less in most instances.

\section{Medications pre and post IBS, AP or IBD}

Table 3 shows the number of NICE guideline recommended medications for IBS prescribed in the year prior to and after the index episode of IBS, AP and IBD. NICE guideline recommended medications for IBS were prescribed for $31 \%$ and $54 \%$ of patients in the year prior to and after their index episode of IBS respectively. The increased use of these medications was most marked for antispasmodics which increased from $17 \%$ in the year prior to IBS to $44 \%$ in the year after. IBS NICE guideline recommended medications were also commonly prescribed in patients with AP and IBD, with about a third of patients being prescribed medications in the year after the index episode of AP or IBD. Prescribing of antispasmodics increased markedly from $5 \%$ to $19 \%$ in those with AP pre- and post- the index episode. Approximately $10 \%$ of patients with IBS, AP or IBD were prescribed selective serotonin reuptake inhibitors (SSRIs), and about 5\% tricyclic antidepressants.

Tables 4 and 5 show the number of NICE guideline recommended medications prescribed in the year prior to and year after the index episodes of IBS, AP and IBD for those with and without symptoms respectively. Where GI symptoms were recorded in the year prior to or the year after the index episode, the proportion of patients prescribed NICE guideline recommended medications was higher than in those without symptoms. However, a number of patients still received NICE guideline recommended medications in the year prior to their index episode of IBS (22\%), AP (18\%) or IBD (20\%) 
Table 3 Number (\%) of medications pre and post IBS, AP and IBD, Salford 2002-2011

\begin{tabular}{|c|c|c|c|c|c|c|c|c|c|c|c|c|}
\hline \multirow[b]{2}{*}{ Medications $^{\dagger}$} & \multicolumn{2}{|c|}{$\begin{array}{c}\text { Pre IBS } \\
(n=7728)\end{array}$} & \multicolumn{2}{|c|}{$\begin{array}{c}\text { Post IBS } \\
(n=7665)\end{array}$} & \multicolumn{2}{|c|}{$\begin{array}{c}\text { Pre AP } \\
(n=39974)\end{array}$} & \multicolumn{2}{|c|}{$\begin{array}{c}\text { Post AP } \\
(\mathrm{n}=37851)\end{array}$} & \multicolumn{2}{|c|}{$\begin{array}{c}\text { Pre IBD } \\
(n=1336)\end{array}$} & \multicolumn{2}{|c|}{$\begin{array}{l}\text { Post IBD } \\
(n=1382)\end{array}$} \\
\hline & $\mathrm{n}$ & $\%$ & $\mathrm{n}$ & $\%$ & $\mathrm{n}$ & $\%$ & $\mathrm{n}$ & $\%$ & $\mathrm{n}$ & $\%$ & $\mathrm{n}$ & $\%$ \\
\hline NICE medications & 2395 & 31.0 & 4099 & 53.5 & 8560 & 21.4 & 13871 & 36.6 & 389 & 29.1 & 442 & 32.0 \\
\hline Bulking laxatives & 288 & 3.7 & 629 & 8.2 & 754 & 1.9 & 1561 & 4.1 & 40 & 3.0 & 50 & 3.6 \\
\hline Stimulant laxatives & 204 & 2.6 & 247 & 3.2 & 1106 & 2.8 & 1688 & 4.5 & 36 & 2.7 & 59 & 4.3 \\
\hline Faecal softeners & 0 & 0.0 & 0 & 0.0 & 0 & 0.0 & 0 & 0.0 & 0 & 0.0 & 0 & 0.0 \\
\hline Osmotic laxatives & 216 & 2.8 & 289 & 3.8 & 845 & 2.1 & 1550 & 4.1 & 27 & 2.0 & 50 & 3.6 \\
\hline Antimotility drugs & 246 & 3.2 & 429 & 5.6 & 727 & 1.8 & 979 & 2.6 & 132 & 9.9 & 169 & 12.2 \\
\hline Antispasmodic drugs & 1328 & 17.2 & 3397 & 44.3 & 1890 & 4.7 & 7035 & 18.6 & 157 & 11.8 & 149 & 10.8 \\
\hline Tricyclic antidepressants & 397 & 5.1 & 553 & 7.2 & 1924 & 4.8 & 2221 & 5.9 & 66 & 4.9 & 78 & 5.6 \\
\hline SSRI & 808 & 10.5 & 957 & 12.5 & 3530 & 8.8 & 3955 & 10.4 & 101 & 7.6 & 129 & 9.3 \\
\hline Other antidepressants & 124 & 1.6 & 147 & 1.9 & 554 & 1.4 & 660 & 1.7 & 12 & 0.9 & 15 & 1.1 \\
\hline
\end{tabular}

${ }^{\dagger}$ Medications on the same day were coded as post.

despite not having any symptoms recorded in the year prior to their index episode. In those with IBS approximately $50 \%$ of those with no symptoms recorded in the year after their index episode were prescribed NICE guideline recommended medications, compared with about $30 \%$ in those with AP or IBD. In those where symptoms had been recorded in the year prior to or after the index episode the proportion prescribed NICE guideline recommended medications was much higher compared to those where no symptoms had been recorded.

\section{Referrals pre and post IBS, AP or IBD}

About $4 \%$ of patients had a gastrointestinal secondary care referral either in the year prior to or the year after their index episode of IBS (Table 6). This was in contrast to patients with IBD where $9 \%$ of patients had a GI referral in the year prior to their index episode and 22\% had a GI referral in the year after their index episode. Few patients $(0.9 \%)$ with AP had a GI referral in the year prior to their index episode. The number of referrals for mental health or lifestyle was low $(0.0 \%$ to $0.7 \%)$ for all three conditions.

\section{Discussion}

\section{Summary}

This database study demonstrated that the prevalence of IBS in patients who consult, and are recorded by, their GP was low compared with the reported prevalence rates in the literature [2]. Most patients who had an IBS Read Code recorded did not have any gastrointestinal symptoms recorded prior to or after their index date. Likewise the majority of patients with AP or IBD did not have any symptoms recorded prior to or after their index

Table 4 Number (\%) of medications pre and post IBS, AP, IBD in those with no symptoms, Salford 2002-2011

\begin{tabular}{|c|c|c|c|c|c|c|c|c|c|c|c|c|}
\hline \multirow[b]{2}{*}{ Medications $^{\dagger}$} & \multicolumn{2}{|c|}{$\begin{array}{c}\text { Pre IBS } \\
(n=5367)\end{array}$} & \multicolumn{2}{|c|}{$\begin{array}{c}\text { Post IBS } \\
(n=6062)\end{array}$} & \multicolumn{2}{|c|}{$\begin{array}{c}\text { Pre AP } \\
(\mathrm{n}=36670)\end{array}$} & \multicolumn{2}{|c|}{$\begin{array}{c}\text { Post AP } \\
(\mathrm{n}=27010)\end{array}$} & \multicolumn{2}{|c|}{$\begin{array}{l}\text { Pre IBD } \\
(\mathrm{n}=930)\end{array}$} & \multicolumn{2}{|c|}{$\begin{array}{l}\text { Post IBD } \\
(n=1143)\end{array}$} \\
\hline & $\mathrm{n}$ & $\%$ & $\mathrm{n}$ & $\%$ & $\mathrm{n}$ & $\%$ & $\mathrm{n}$ & $\%$ & $\mathrm{n}$ & $\%$ & $\mathrm{n}$ & $\%$ \\
\hline NICE medications & 1176 & 21.9 & 2974 & 49.1 & 6720 & 18.3 & 8018 & 29.7 & 191 & 19.9 & 300 & 26.2 \\
\hline Bulking laxatives & 119 & 2.2 & 437 & 7.2 & 569 & 1.6 & 840 & 3.1 & 21 & 2.2 & 32 & 2.8 \\
\hline Stimulant laxatives & 77 & 1.4 & 129 & 2.1 & 795 & 2.2 & 896 & 3.3 & 19 & 2.0 & 33 & 2.9 \\
\hline Faecal softeners & 0 & 0.0 & 0 & 0.0 & 0 & 0.0 & 0 & 0.0 & 0 & 0.0 & 0 & 0.0 \\
\hline Osmotic laxatives ${ }^{\ddagger}$ & 93 & 1.7 & 152 & 2.5 & 571 & 1.6 & 745 & 2.8 & 13 & 1.4 & 25 & 2.2 \\
\hline Antimotility drugs & 109 & 2.0 & 284 & 4.7 & 423 & 1.2 & 450 & 1.7 & 66 & 6.9 & 119 & 10.4 \\
\hline Antispasmodic drugs & 533 & 9.9 & 2430 & 40.1 & 1414 & 3.9 & 3870 & 14.3 & 55 & 5.7 & 85 & 7.4 \\
\hline Tricyclic antidepressants & 228 & 4.2 & 372 & 6.1 & 1647 & 4.5 & 1364 & 5.0 & 46 & 4.8 & 52 & 4.5 \\
\hline SSRI & 471 & 8.8 & 680 & 11.2 & 3061 & 8.3 & 2488 & 9.2 & 59 & 6.1 & 92 & 8.0 \\
\hline Other antidepressants & 55 & 1.0 & 84 & 1.4 & 472 & 1.3 & 383 & 1.4 & 8 & 0.8 & 10 & 0.9 \\
\hline
\end{tabular}

${ }^{\dagger}$ Medications on the same day were coded as post.

${ }^{\ddagger}$ Excludes lactulose which is not recommended in NICE guidelines. 
Table 5 Number (\%) of medications pre and post IBS, AP, IBD in those with symptoms, Salford 2002-2011

\begin{tabular}{|c|c|c|c|c|c|c|c|c|c|c|c|c|}
\hline \multirow[b]{2}{*}{ Medications $^{\dagger}$} & \multicolumn{2}{|c|}{$\begin{array}{c}\text { Pre IBS } \\
(n=2361)\end{array}$} & \multicolumn{2}{|c|}{$\begin{array}{c}\text { Post IBS } \\
(n=1603)\end{array}$} & \multicolumn{2}{|c|}{$\begin{array}{c}\text { Pre AP } \\
(n=3304)\end{array}$} & \multicolumn{2}{|c|}{$\begin{array}{c}\text { Post AP } \\
(\mathrm{n}=10841)\end{array}$} & \multicolumn{2}{|c|}{$\begin{array}{c}\text { Pre IBD } \\
(\mathrm{n}=406)\end{array}$} & \multicolumn{2}{|c|}{$\begin{array}{l}\text { Post IBD } \\
(n=239)\end{array}$} \\
\hline & $\mathrm{n}$ & $\%$ & $\mathrm{n}$ & $\%$ & $\mathrm{n}$ & $\%$ & $\mathrm{n}$ & $\%$ & $\mathbf{n}$ & $\%$ & $\mathrm{n}$ & $\%$ \\
\hline NICE medications & 1181 & 50.0 & 1103 & 68.8 & 1466 & 44.4 & 5314 & 49.0 & 189 & 46.6 & 135 & 56.5 \\
\hline Bulking laxatives & 169 & 7.2 & 192 & 12.0 & 185 & 5.6 & 721 & 6.7 & 19 & 4.7 & 18 & 7.5 \\
\hline Stimulant laxatives & 127 & 5.4 & 118 & 7.4 & 311 & 9.4 & 792 & 7.3 & 17 & 4.2 & 26 & 10.9 \\
\hline Faecal softeners & 0 & 0.0 & 0 & 0.0 & 0 & 0.0 & 0 & 0.0 & 0 & 0.0 & 0 & 0.0 \\
\hline Osmotic laxatives $^{\ddagger}$ & 123 & 5.2 & 137 & 8.5 & 274 & 8.3 & 805 & 7.4 & 14 & 3.4 & 25 & 10.5 \\
\hline Antimotility drugs & 137 & 5.8 & 145 & 9.0 & 304 & 9.2 & 529 & 4.9 & 66 & 16.3 & 50 & 20.9 \\
\hline Antispasmodic drugs & 795 & 33.7 & 967 & 60.3 & 476 & 14.4 & 3165 & 29.2 & 102 & 25.1 & 64 & 26.8 \\
\hline Tricyclic antidepressants & 169 & 7.2 & 181 & 11.3 & 277 & 8.4 & 857 & 7.9 & 20 & 4.9 & 26 & 10.9 \\
\hline SSRI & 337 & 14.3 & 277 & 17.3 & 469 & 14.2 & 1467 & 13.5 & 42 & 10.3 & 37 & 15.5 \\
\hline Other antidepressants & 69 & 2.9 & 63 & 3.9 & 82 & 2.5 & 277 & 2.6 & 4 & 1.0 & 5 & 2.1 \\
\hline
\end{tabular}

${ }^{\dagger}$ Medications on the same day were coded as post.

${ }^{\ddagger}$ Excludes lactulose which is not recommended in NICE guidelines.

date. Antispasmodics were the most commonly prescribed medications for patients with IBS. A significant proportion of patients were prescribed IBS NICE guideline recommended medications in the year prior to their IBS being Read Coded. A small proportion of patients with IBS were referred to GI specialists.

\section{Strengths and limitations}

A major advantage of the SIR is the complete linkage between primary care, community care and secondary care datasets, providing a continuous electronic record for each patient in contact with health services in Salford. However, there were certain limitations in using these data for identifying patients with IBS in our study.

We were unable to validate the dataset. Ideally we would have created a cohort of IBS patients from SIR and validated the diagnosis by asking their GPs [10] but this was not possible since the SIR for research is anonymised at both patient and GP level. In addition, a number of computerised systems are available for capturing clinical consultation data in primary care and several different versions of the various operating systems are in use so there may be slight variations at computer operating system level that would have impeded our research.

There are also idiosyncrasies in the Read Code taxonomy, in particular the fact that codes for a lack of existence of a symptom can occur as leaf nodes describing that symptom. For example, the Read Code for "no abdominal pain" (1961.) is included under one of the Read Codes for abdominal pain (196..). However, it seems that GPs might be reluctant to document patients using such negated child node Read Codes as less than $0.1 \%$ were found in the data set we used.

Read Codes used to code a consultation are at the discretion of the individual clinician, which means that there can be considerable variation in their use to describe the same set of symptoms in practice (particularly for conditions not incentivised in the Quality Outcomes Framework (QOF)). However, research requires a disciplined approach to data entry and retrieval [11], so that inconsistency in coding potentially presents an important source of information bias.

\section{Recorded prevalence of IBS consultations}

This study demonstrates that the recorded prevalence of IBS in patients who consult their GP is low. In the current study, we not only looked at the prevalence of IBS Read Codes in primary care, but the prevalence of AP, the main presenting feature for IBS. Even rates of AP were less than those reported for IBS in the literature. Reassuringly we found similar results using data extracted from Manchester Primary Care Organisation (data not shown) suggesting that the current findings are not an artefact of

Table 6 Number (\%) of referrals pre and post IBS, AP and IBD, Salford 2002-2011

\begin{tabular}{|c|c|c|c|c|c|c|c|c|c|c|c|c|}
\hline \multirow[b]{2}{*}{ Referrals $^{\#}$} & \multicolumn{2}{|c|}{$\begin{array}{c}\text { Pre IBS } \\
(n=7728)\end{array}$} & \multicolumn{2}{|c|}{$\begin{array}{c}\text { Post IBS } \\
(\mathrm{n}=7665)\end{array}$} & \multicolumn{2}{|c|}{$\begin{array}{c}\text { Pre AP } \\
(\mathrm{n}=39974)\end{array}$} & \multicolumn{2}{|c|}{$\begin{array}{c}\text { Post AP } \\
(n=37851)\end{array}$} & \multicolumn{2}{|c|}{$\begin{array}{c}\text { Pre IBD } \\
(n=1336)\end{array}$} & \multicolumn{2}{|c|}{$\begin{array}{l}\text { Post IBD } \\
(n=1382)\end{array}$} \\
\hline & $\mathrm{n}$ & $\%$ & $\mathrm{n}$ & $\%$ & $\mathrm{n}$ & $\%$ & $\mathrm{n}$ & $\%$ & $\mathrm{n}$ & $\%$ & $\mathrm{n}$ & $\%$ \\
\hline Gastrointestinal & 295 & 3.8 & 288 & 3.8 & 358 & 0.9 & 1230 & 3.2 & 123 & 9.2 & 303 & 21.9 \\
\hline Mental health & 3 & 0.0 & 3 & 0.0 & 19 & 0.0 & 21 & 0.1 & 0 & 0.0 & 0 & 0.0 \\
\hline Lifestyle & 24 & 0.3 & 24 & 0.3 & 79 & 0.2 & 99 & 0.3 & 6 & 0.4 & 9 & 0.7 \\
\hline
\end{tabular}

"Referrals on the same day were coded as post. 
the data (Thompson DG, O'Brien S, Kennedy A, Rogers A, Whorwell P, Lovell K, et al:: Evaluating and Implementing Better Patient-Orientated Management of Chronic Gastrointestinal Disorders in Primary Care. Programme Grants Appl Res 2014, in review).

There are several possible explanations for the lower than expected prevalence of patients consulting with, and recorded as having, IBS.

Firstly, many of the studies estimating the prevalence of IBS have been self-report questionnaire surveys, and may have overestimated the proportion of patients who have been formally diagnosed with IBS, or who seek healthcare for their symptoms. Nevertheless the consultation prevalence for IBS was much lower than expected and the literature suggests that GPs see IBS as a significant problem [12]. Our findings reflect those in rheumatology where large discrepancies have been found in the consultation prevalence of knee pain when comparing primary care records with patient recall [13]. These discrepancies are as a result of 'telescoping' by patients and under recording by GPs, in particular, if patients present with multiple problems or have previously consulted for the same condition [13]. Like knee pain, IBS does not have a definite diagnosis and symptoms fluctuate over time, thus primary care records may only reflect the consultation prevalence of IBS when it forms a major part of the consultation. Moreover, Jordan at el. [13] found that consultation rates increased when the text of the consultation was used in addition to Read Codes alone. Others have also discussed the benefit of narratives during the consultation rather than reducing the clinical encounter to a limited number of codes [14].

Secondly, IBS or GI symptoms, are not included in the Quality Outcomes Framework (QoF), a scheme that incentivises GP practices and rewards them according to how well they care for patients. Consequently, recording IBS is not likely to be a priority for GPs and therefore may be patchy.

Thirdly, GPs appear to be reluctant to code patients for IBS or lower GI symptoms. The IBS diagnosis in primary care appears to be different to, and less exclusive than existing diagnostic criteria [15]. The usefulness of diagnostic criteria is frequently debated in the literature [16-20] and they tend to be of little relevance within primary care, as few GPs are familiar with the criteria and they do not use them to make a diagnosis $[17,21,22]$. In our qualitative study to investigate how GPs defined, diagnosed and managed patients with IBS, we found that whilst most GPs were aware of the NICE guideline [4] for IBS, few used it to help them make a diagnosis of IBS and add a Read Code to the patient record [6]. Instead they described using an iterative process to exclude sinister symptoms and as a result perhaps not applying a Read Code to the patient record when they first consult.
Fourthly, recorded prevalence depends on the healthcare seeking behaviour of patients. Patients may not consult their GP for IBS for a number of reasons. They may only consult when their symptoms are severe and, consequently, they perhaps feel less able to cope. Indeed, data from our risk assessment study, where patients were recruited either via the consultation or through the use of Read Code searches (and had to have consulted for IBS symptoms in the last three months), suggest that the majority of patients had moderate or severe symptoms (Thompson DG, O'Brien S, Kennedy A, Rogers A, Whorwell $\mathrm{P}$, Lovell $\mathrm{K}$, et al.: Evaluating and Implementing Better Patient-Orientated Management of Chronic Gastrointestinal Disorders in Primary Care. Programme Grants Appl Res 2014, in review). Evidence suggests that symptom severity may have an influence on health care seeking but that it does explain the majority of the consultation behaviour [23]. Psychological and psychosocial factors have also been implicated in health care seeking behaviours for patients with IBS [24,25]. The present study suggests that a proportion of patients with IBS, AP and IBD were prescribed anti-depressants in the year before and the year after their index episode. However, we cannot infer whether these medications were prescribed for their gastrointestinal symptoms, for related anxiety and/or depression, or for unrelated anxiety and/or depression.

Furthermore, patients may not consult their GP for their IBS because their symptoms are under control through the use of medication or self-management. A relatively large proportion of patients in the current study had no GI symptoms in the year prior to their index episode of IBS but had been prescribed IBS medications, as recommended in the NICE guideline [4]. However, we are unable to say whether these patients had ever been recorded as having IBS prior to the year before their index episode, and whether they had received a repeat prescription from their GP for their symptoms.

Finally, patients may feel there is little that primary care can offer, and therefore learn to live with their symptoms. Stenner et. al. [26] reported that patients felt that doctors were unsympathetic and ignorant about IBS, and often considered IBS 'all being in the mind' of the patient. Others felt GPs were responsible for the worsening of their condition as a result of their ignorance of IBS or 'through the iatrogenic effects of treatment' [26]. Farndale et al. [27] found that IBS patients report alienation from health services for similar reasons. In addition, moderate to high levels of perceived stigma are significantly greater in IBS patients $(27 \%)$ compared to IBD patients (8\%), with the largest difference being for health care providers [28]. It is, therefore, perhaps unsurprising that a proportion of those suffering from the symptoms of IBS do not consult their GP and 
decide to self-medicate and/or seek alternative therapies. Although alternative therapies are not recommended within the NICE guidance [4] our qualitative study showed that GPs did not discourage their use [6].

\section{IBS and GI symptoms}

Our study found that the majority of patients who were coded as having IBS did not have GI symptoms recorded in the year prior to or the year after their index episode. NICE recommends assessment for IBS in patients having any of the following for at least 6 months: abdominal pain or discomfort, bloating or change in bowel habit. Therefore one might expect evidence of this in the recording of symptom codes in the year prior to or after the index episode of IBS. However, this was not the case, despite using symptom codes in order to be as comprehensive as possible and by including other related symptoms, such as nausea and vomiting, tenesmus and faeces/ motions. Interestingly though, IBS medications as recommended by NICE were often prescribed in those without recorded symptoms in the year prior to their IBS. GPs in the qualitative study also described making a diagnosis based on the patient response to a trial of medication [6]. This suggests that the use of medication codes may be an alternative approach to identifying patients via symptom or diagnostic Read Codes. GPs must enter a medication on their clinical system in order for a prescription to be issued. However this approach may include patients with other diagnoses as some IBS medications (e.g. laxatives) may also be prescribed for other conditions.

Findings from our qualitative study suggest GPs did not describe difficulties in managing patients with IBS [6]. This is also evident in the current study where a relatively small proportion of patients with IBS had a referral to a GI specialist, compared to those patients with a diagnosis of IBD.

\section{Similarities with other medically unexplained symptoms}

Similarities can be seen with other medically unexplained symptoms such as fibromyalgia and chronic fatigue syndrome. For example, Rohrbeck et al. [29] found the recorded annual prevalence of fibromyalgia in primary care to be 8 per 10000 which is much lower than the estimated general population prevalence of $2 \%$. This implies that the label of fibromyalgia is rarely used within general practice [29]. They also found that fibromyalgia patients are similar to those with overlapping functional syndromes or medically unexplained symptoms [29]. Similarly, in his review of medically unexplained symptoms in primary care, Burton [30] reported that many patients with IBS met the criteria for fibromyalgia and chronic pelvic pain. This overlap with other medically unexplained symptoms, which often appear to share similar psychosocial characteristics, creates further diagnostic complexities.

\section{Conclusions}

Our findings suggest that the use of symptom /and or diagnostic Read Codes to identify patients with IBS in primary care is questionable and likely to lead to large underestimates of both the community incidence and prevalence. The discrepancies between the self-reported prevalence rates in the literature and those for consultations within the primary care record, suggest that there may be conflicting priorities between patients and health care professionals, and that database studies, are useful in only identifying the 'tip of the iceberg'.

\section{NIHR disclaimer}

This paper presents independent research commissioned by the National Institute for Health Research (NIHR) under its Programme Grants for Applied Research funding scheme (RP-PG-0407-10136). The views expressed in this paper are those of the authors and not necessarily those of the NHS, NIHR or the Department of Health.

\section{Ethics approval}

Ethical permission for this study was granted by the North West e-Health Board (Reference 177), and the individual healthcare organisations.

\section{Appendix}

Tables 7, 8 and 9 .

Table 7 Symptoms/diagnoses were defined as any of the following

\begin{tabular}{lll}
\hline Symptom/diagnoses & $\begin{array}{l}\text { Read } \\
\text { codes }\end{array}$ & Rubric \\
\hline Irritable bowel syndrome & 14CF. & History of IBS \\
& J521. & IBS \\
Abdominal pain & $196 .$. & Type of gastrointestinal tract pain \\
& 197.. & Site of gastrointestinal tract pain \\
& R090. & [D] Abdominal pain \\
Bloating & 19A.. & Abdominal distension symptom \\
& 19B.. & Flatulence/wind \\
& R0734 & [D] Bloating \\
Constipation symptom & 19C.. & Constipation \\
Functional constipation & J520. & Constipation - functional \\
Change in bowel habit & 19EA. & Change in bowel habit \\
& R078. & [D] Change in bowel habit \\
& 19F.. & Diarrhoea symptoms \\
Diarrhoea & 19G.. & Diarrhoea and vomiting \\
& J525. & Functional diarrhoea \\
& J43z. & Chronic diarrhoea \\
Functional diarrhoea & J4Z.. & Presumed noninfectious diarrhoea
\end{tabular}


Table 7 Symptoms/diagnoses were defined as any of the following (Continued)

\begin{tabular}{|c|c|c|}
\hline Nausea & 198. & Nausea \\
\hline Vomiting & 199. & Vomiting \\
\hline Diarrhoea and vomiting & 19G.. & Diarrhoea and vomiting \\
\hline Tenesmus & 19D.. & Tenesmus symptom \\
\hline $\begin{array}{l}\text { Faeces/motions } \\
\text { symptoms }\end{array}$ & 19E.. & Faeces/motions -symptoms \\
\hline Gl infection & $\mathrm{A} 0 \ldots$ & Intestinal infectious diseases \\
\hline \multirow{2}{*}{$\begin{array}{l}\text { Inflammatory bowel } \\
\text { disease }\end{array}$} & J40.. & Crohn's disease \\
\hline & J41.. & Ulcerative colitis or proctitis \\
\hline
\end{tabular}

Table 8 Medications were defined on the basis of the NICE guidelines [4] and were coded as follows

\begin{tabular}{lll}
\hline NICE medications & $\begin{array}{l}\text { Read } \\
\text { codes }\end{array}$ & Rubric \\
\hline Bulk-forming laxatives & ab2.. & Isphagula husk \\
& ab3.. & Methylcellulose \\
ab4.. & Sterculia \\
Stimulant laxatives & ac5.. & Docusate sodium \\
ac7.. & Senna \\
ac8.. & Sodium picosulphate \\
af1.. & Rectal laxatives (Glycerol, biascodyl) \\
ac1.. & Biascodyl \\
Osmotic laxatives & ad1.. & Liquid paraffin \\
& ae4.. & Polyethylene glycols \\
a12.. & Magnesium salts - antacid \\
ae2.. & Magnesium hydroxide \\
ae3.. & Magnesium sulphate \\
ae7.. & Sodium phosphate \\
a81.. & Codeine phosphate \\
a82.. & Diphenoxylate hydrochloride \\
a83.. & Loperamide: single drug \\
a85.. & Loperamide: compound preparation \\
a842. & Kaolin and morphine mixture \\
a41.. & Atrophine sulphate \\
a45.. & Dicycloverine hydrochloride \\
a47.. & Hyoscine butylbromide \\
a4c.. & Propantheline bromide \\
a4d.. & Alverine citrate \\
a4e.. & Mebeverine hydrochloride \\
a4f.. & Peppermint oil \\
& & \\
& &
\end{tabular}

Antidepressants

Tricyclics and related antidepressants d71.. Amitripyline

d91.. Triptafen
Table 8 Medications were defined on the basis of the NICE guidelines [4] and were coded as follows (Continued)

\begin{tabular}{|c|c|c|}
\hline & d73.. & Clomipramine hydrochloride \\
\hline & d75.. & Dosulephin hydrochloride \\
\hline & d76.. & Doxepin \\
\hline & d77.. & Imipramine hydrochloride \\
\hline & d79.. & Lofepramine \\
\hline & $d 7 c .$. & Nortriptyline \\
\hline & d7f.. & Trimipramine \\
\hline & $d 7 b$. & Mianserin hydrochloride \\
\hline & d7e.. & Trazodone hydrochloride \\
\hline Selective serotonin & da9.. & Citalopram \\
\hline re-uptake inhibitors (SSRIs) & $\mathrm{daC} .$. & Escitalopram \\
\hline $\begin{array}{l}\text { Monoamine oxidase } \\
\text { inhibitors (MAOls) }\end{array}$ & da4.. & Fluoxetine hydrochloride \\
\hline Reversible MAOls & da3.. & Fluvoxamine maleate \\
\hline & da6.. & Paroxetine hydrochloride \\
\hline & da5.. & Sertraline hydrochloride \\
\hline Other antidepressants & d81.. & Phenelzine \\
\hline & d83.. & Isocarboxazid \\
\hline & d84.. & Tranylcypromine \\
\hline & d85.. & Moclobemide \\
\hline & gde.. & Duloxetine \\
\hline & da1.. & Flupentixol \\
\hline & daB.. & Mirtazapine \\
\hline & daA.. & Reboxetine \\
\hline & da2.. & Tryptophan \\
\hline
\end{tabular}

Table 9 Referrals to specialists or for further for investigation of gastrointestinal symptoms were defined as any of the following

\begin{tabular}{|c|c|c|}
\hline Referral & $\begin{array}{l}\text { Read } \\
\text { codes }\end{array}$ & Rubric \\
\hline \multirow{13}{*}{$\begin{array}{l}\text { Specialist } \\
\text { referral }\end{array}$} & $8 h 48$. & Gastroenterological referral \\
\hline & 8h5」. & Referral to colorectal surgeon \\
\hline & $8 \mathrm{H} 5 \mathrm{~K}$ & Referral to upper gastrointestinal surgeon \\
\hline & 8HL8. & Gastroenterology DV done \\
\hline & 8HM8. & Listed for gasterenterol admis \\
\hline & $8 \mathrm{Hn} 4$. & Fast track referral for suspected colorectal cancer \\
\hline & $8 \mathrm{Hn} 9$. & Fast track referral for suspected upper Gl cancer \\
\hline & 8HS.. & Refer for gastroscopy \\
\hline & 8HSO. & Refer for sigmoidoscopy \\
\hline & 8HU1. & Referral for colonoscopy \\
\hline & $8 \mathrm{HU} 2$. & Referral for sigmoidoscopy \\
\hline & $8 \mathrm{HVC}$ & Private referral to colorectal surgeon \\
\hline & 8HVN. & Private referral to gastroenterologist \\
\hline
\end{tabular}




\section{Competing interests}

The authors declare that they have no competing interests.

\section{Authors' contributions}

EFH participated in the study design, supervised the data analysis, and led writing the paper. LG participated in data analysis and contributed to writing the paper. SJO'B participated in the study design and contributed to writing the paper. DGT participated in study design and contributed writing the paper. CCG contributed to writing the paper and led on the qualitative study. All authors read and approved the final manuscript.

\section{Acknowledgement}

On behalf of the Salford NIHR GI Programme Grant Research Group: Karen Armstrong, David Backhouse, Paula Beech, Peter Bower, Carolyn Chew-Graham, Andrew Clough, Anne Kennedy, Karina Lovell, Jim Nuttall, Sarah O'Brien, Karen Procter, David Reeves, Gerry Richardson, Anne Rogers, David Thompson, and Peter Whorwell.

EFH, LG, DGT and CCG were supported by the University of Manchester, Faculty of Medical \& Health Sciences and the Manchester Academic Health Science Centre (MAHSC) at the time of the study.

\section{Author details}

${ }^{1}$ Institute of Inflammation and Repair, Stopford Building, University of Manchester, Oxford Road, Manchester M13 9PL, UK. ${ }^{2}$ Institute of Infection and Global Health, Leahurst Campus, University of Liverpool, Chester High Road, Neston, South Wirral CH64 7TE, UK. ${ }^{3}$ Research Institute, Primary Care and Health Sciences, Keele University, Keele, Staffordshire ST5 5BG, UK. ${ }^{4}$ Gastrointestinal Centre, Institute of Inflammation \& Repair, University of Manchester, Clinical Sciences Building, Salford Royal NHS Foundation Trust, Stott Lane, Salford M6 8HD, UK.

Received: 7 August 2013 Accepted: 20 November 2013 Published: 2 December 2013

\section{References}

1. Longstreth GF, Thompson WG, Chey WD, Houghton LA, Mearin F, Spiller RC: Functional bowel disorders. Gastroenterology 2006, 130:1480-1491.

2. Rey E, Talley NJ: Irritable bowel syndrome: novel views on the epidemiology and potential risk factors. Dig Liver Dis 2009, 41:772-780.

3. Wilson $S$, Roberts $L$, Roalfe A, Bridge P, Singh S: Prevalence of irritable bowel syndrome: a community survey. Br J Gen Pract 2004, 54:495-502.

4. National Institute for Health and Clinical Excellence: NICE Clinical Guideline 61: Irritable Bowel Syndrome in Adults: Diagnosis and Management of Irritable Bowel Syndrome in Primary Care. London: National Institute for Health and Clinical Excellence; 2008.

5. Halder S, Macfarlane GJ, Thompson D, O'Brien SJ, Musleh M, McBeth J: Predictors of persistent gastrointestinal symptoms among new presenters to primary care. Eur J Gastroenterol Hepatol 2010, 22:296-305.

6. Harkness EF, Harrington V, Hinder S, O'Brien SJ, Thompson DG, Beech P, et al: GP perspectives of irritable bowel syndrome - an accepted illness, but management deviates from guidelines: a qualitative study. BMC Fam Pract 2013, 14:92.

7. Jordan K, Porcheret M, Croft P: Quality of morbidity coding in general practice computerized medical records: a systematic review. Fam Pract 2004, 21:396-412.

8. Khan NF, Harrison SE, Rose PW: Validity of diagnostic coding within the general practice research database: a systematic review. Br J Gen Pract 2010, 60:e128-e136.

9. Office for National Statistics: Primary Care Organisation Population Estimates (Experimental), Mid-2010. Fareham: Office for National Statistics licensed under the Open Government Licence v.1.0; 2013.

10. Seminara NM, Abuabara K, Shin DB, Langan SM, Kimmel SE, Margolis D, et al: Validity of the health improvement network (THIN) for the study of psoriasis. Br J Dermatol 2011, 164:602-609.

11. Soler JK, Pringle M: Research using electronic patient records in general practice: the EGPRN meeting in Bertinoro, Italy, May 2009. Eur J Gen Pract 2010, 16:186-189.

12. Thompson WG, Heaton KW, Smyth GT, Smyth C: Irritable bowel syndrome in general practice: prevalence, characteristics, and referral. Gut 2000 46:78-82.
13. Jordan $K$, Jinks C, Croft P: Health care utilization: measurement using primary care records and patient recall both showed bias. J Clin Epidemiol 2006, 59:791-797.

14. Walsh SH: The clinician's perspective on electronic health records and how they can affect patient care. BMJ 2004, 328:1184-1187.

15. Rubin G, de Wit N, Meineche-Schmidt V, Seifert B, Hall N, Hungin P: The diagnosis of IBS in primary care: consensus development using nominal group technique. Fam Pract 2006, 23:687-692

16. Henderson PK, DiPalma JA: Diagnosing irritable bowel syndrome: a changing clinical paradigm: [Review]. Southern Med J 2011, 104:195-199.

17. Mearin F, Lacy BE: Diagnostic criteria in IBS: useful or not? Neurogastroenterol Motil 2012, 24:791-801.

18. Talley NJ: Irritable bowel syndrome: definition, diagnosis and epidemiology. Baillieres Best Pract Res Clin Gastroenterol 1999, 13:371-384.

19. Williams RE, Black CL, Kim HY, Andrews EB, Mangel AW, Buda JJ, et al: Stability of irritable bowel syndrome using a Rome II-based classification. Aliment Pharmacol Ther 2006, 23:197-205.

20. Yale SH, Musana AK, Kieke A, Hayes J, Glurich I, Chyou PH: Applying case definition criteria to irritable bowel syndrome. Clin Med Res 2008, 6:9-16.

21. Lionis C, Olsen-Faresjo A, Anastasiou F, Wallander MA, Johansson S, Faresjo $T$ : Measuring the frequency of functional gastrointestinal disorders in rural Crete: a need for improving primary care physicians' diagnostic skills. Rural Remote Health 2005, 5:409.

22. Ford AC, Talley NJ: Irritable bowel syndrome. BMJ 2012, 345:e5836.

23. Koloski NA, Talley NJ, Boyce PM: Predictors of health care seeking for irritable bowel syndrome and nonulcer dyspepsia: a critical review of the literature on symptom and psychosocial factors. Am J Gastroenterol 2001, 96:1340-1349.

24. Ringstrom G, Abrahamsson $H$, Strid $H$, Simren M: Why do subjects with irritable bowel syndrome seek health care for their symptoms? Scand J Gastroenterol 2007, 42:1194-1203.

25. Koloski NA, Talley NJ, Boyce PM: Epidemiology and health care seeking in the functional GI disorders: a population-based study. Am J Gastroenterol 2002, 97:2290-2299.

26. Stenner PH, Dancey CP, Watts S: The understanding of their illness amongst people with irritable bowel syndrome: a $\mathrm{Q}$ methodological study. Soc Sci Med 2000, 51:439-452.

27. Farndale R, Roberts L: Long-term impact of irritable bowel syndrome: a qualitative study. Prim Health Care Res Dev 2011, 12:52-67.

28. Taft TH, Keefer L, Artz C, Bratten J, Jones MP: Perceptions of illness stigma in patients with inflammatory bowel disease and irritable bowel syndrome. Qual Life Res 2011, 20:1391-1399.

29. Rohrbeck J, Jordan K, Croft P: The frequency and characteristics of chronic widespread pain in general practice: a case-control study. $\mathrm{Br} J$ Gen Pract 2007, 57:109-115.

30. Burton C: Beyond somatisation: a review of the understanding and treatment of medically unexplained physical symptoms (MUPS). $\mathrm{Br} J \mathrm{Gen}$ Pract 2003, 53:231-239.

doi:10.1186/1471-2296-14-183

Cite this article as: Harkness et al.: Using read codes to identify patients with irritable bowel syndrome in general practice: a database study. BMC Family Practice 2013 14:183.

\section{Submit your next manuscript to BioMed Central and take full advantage of:}

- Convenient online submission

- Thorough peer review

- No space constraints or color figure charges

- Immediate publication on acceptance

- Inclusion in PubMed, CAS, Scopus and Google Scholar

- Research which is freely available for redistribution 